Article - Agriculture, Agribusiness and Biotechnology

\title{
Immunogenicity of a Recombinant Gonadotropin- releasing Hormone Associated to the B Subunit of Escherichia coli Heat-labile Enterotoxin Expressed in Pichia pastoris and Escherichia coli Platforms
}

\section{Lívia Budziarek Eslabão'}

https://orcid.org/0000-0002-8446-9185

Neida Lucia Conrad ${ }^{1}$

https://orcid.org/0000-0001-7573-0794

\section{Pedro Machado Medeiros de Albuquerque ${ }^{1}$ https://orcid.org/0000-0001-9311-6050}

\author{
Rodrigo Casquero Cunha ${ }^{2}$ \\ https://orcid.org/0000-0003-0145-0321
}

Antônio Sérgio Varela Junior ${ }^{3}$

https://orcid.org/0000-0003-4901-5118

Fábio Pereira Leivas Leite ${ }^{1,2 *}$

https://orcid.org/0000-0003-0941-7286

${ }^{1}$ Federal University of Pelotas, Biotechnology-Technological Development Center, Pelotas, Rio Grande do Sul, Brazil; ${ }^{2}$ Federal University of Pelotas, Faculty of Veterinary Medicine, Pelotas, Rio Grande do Sul, Brazil; ${ }^{3}$ Federal University of Pelotas, Biological science Institute, Pelotas, Rio Grande do Sul, Brazil.

Editor-in-Chief: Alexandre Aoki

Associate Editor: Renata Marino Romano

Received: 2021.03.10; Accepted: 2021.08.16.

*Correspondence: fleivasleite@gmail.com; fabio_leite@ufpel.edu.br; Tel.: +55 53991276663 (F.P.L.L.).

HIGHLIGHTS

- $\quad$ P. pastoris and E. coli systems were able to express $\mathrm{GnRH} / \mathrm{LTB}$;

- Fusion of singles $\mathrm{GnRH}$ and LTB molecules are immunogenic in mice;

- GnRH vaccine induces histological changes on mice gonads;

- $\mathrm{GnRH/LTB}$ molecule is a promising antigen for an immunocontraceptive vaccine.

Abstract: Gonadotropin-releasing hormone $(\mathrm{GnRH})$ is one of the main targets for the development of immunocontraceptives vaccines. The aim of this study was to clone and express the recombinant $\mathrm{GnRH}$ fused to the B subunit of Escherichia coli heat-labile enterotoxin (LTB) molecule in Pichia pastoris and Escherichia coli platforms and evaluate their immunogenicity in mice. P. pastoris (pGnRH/LTB) and E. coli (eGnRH/LTB) platforms were able to express $\mathrm{GnRH} / \mathrm{LTB}$ expected band with $21 \mathrm{kDa}$. Both constructions were immunogenic in mice. Similar IgG kinetics was observed for both construction when it was used as ELISA antigen respectively, showing significant $(p<0.05)$ lgG levels 5 -fold higher than a commercial vaccine and 14-fold higher than the controls. The histological effects of $\mathrm{pGnRH/LTB}$ as well as eGnRH/LTB proteins demonstrated a significant effect on the gonads, characterized by atrophy of seminiferous tubules, absence of spermatogenesis and reduction of Leydig cells. Both constructions were able to induce antibodies that block the hormone effect, suggesting the potential of $\mathrm{GnRH} / \mathrm{LTB}$, independently of the $P$. pastoris or E. coli platform used, as a vaccine candidate for immunocontraception. 
Keywords: recombinant vaccine; contraception; GnRH; Pichia pastoris; Escherichia coli.

\section{INTRODUCTION}

Immunocontraceptive vaccines in general fall in three categories: 1. inhibition of gamete production, through antibodies that interfere in the gametes (male and female) production, inhibiting fertility; 2 . inhibition of gamete function, male (spermatozoon) and female (egg), which immune response can be elicited against gametes specific antigens, causing infertility; 3. inhibition of gamete outcome, the embryo secretes chorionic gonadotropin (CG) which is crucial for established and maintenance of pregnancy, antibodies against $C G$ can interfere in blastocyst implantation, leading to infertility $[1,2]$.

Gonadotropin-releasing hormone $(\mathrm{GnRH})$ is responsible for regulating the biosynthesis and release of luteinizing hormone (LH) and follicle stimulating hormone (FSH), which will act promoting the maturation of ovarian follicles in females and spermatogenesis in males [3]. Thus, making the $\mathrm{GnRH}$ one of the main targets for the development of immunocontraceptives. However, due to its low immunogenicity, GnRH needs to be presented to the immune system as multiple linear alignment copies associated with a carrier molecule for induced appropriated immune response [1].

The heat-labile enterotoxin B subunit of Escherichia coli (LTB) has been used as a carrier molecular characterized by being an effective molecule capable of stimulate a systemic and a mucosal antibodies response [4]. The adjuvancity activity of LTB is mediated by its binding to GM1 ganglioside receptor, present on antigen presenting cells (APCs) [5]. Thus, using recombinant LTB as a carrier protein, with adjuvant proprieties, represent an alternative approach to develop a new immunocontraceptive vaccine.

Recombinant proteins can be obtained through expression in a prokaryotic or eukaryotic platform, maintaining biological characteristics and functions similar to native proteins. $E$. coli has been extensively used as a host for heterologous protein expression, but the system potential limitations includes folding and post-translational modifications of the recombinant protein [6]. Methylotrophic yeast, Pichia pastoris, has been used effectively for the expression of heterologous proteins, mainly due to the ability to promote posttranslational modifications and to secrete heterologous proteins in soluble form [7].

The objective of the present study was to clone and express a recombinant molecule composed by the fusion of singles $\mathrm{GnRH}$ and LTB molecules in $P$. pastoris and $E$. coli systems and evaluate their immunogenicity in mice.

\section{MATERIAL AND METHODS}

\section{GnRH/LTB Pichia pastoris expression (pGnRH/LTB)}

The gene fragment encoding the $\mathrm{GnRH}$ fused to carrier protein LTB was designed based on GenBank sequences, found under accession numbers S60731.1 and AF031653.1, respectively. The GnRH/LTB sequence was synthesized by Epoch Life Science according to the codon preference of $P$. pastoris. To clone the sequence into the pPICZaB expression vector (Invitrogen), the restriction sites EcoRI and Xbal were added upstream and downstream of the gene, respectively. A spacer sequence (Lys-Val-Pro-Arg-AlaAla-Ala) was included between the GnRH and LTB sequences to enable proper folding of each molecule [8].

The recombinant plasmid $\mathrm{pPICZaB} / \mathrm{GnRH} / \mathrm{LTB}$ was linearized with Pmel and transformed into competent cells of the $P$. pastoris X-33 strain by electroporation, according to the manufacturer's instructions (Pichia Expression Kit Manual, Invitrogen Life Technologies, cat. No. K1740-01). After transformation, cells were placed on YPD (1\% yeast extract, $2 \%$ peptone, $2 \%$ dextrose, $2 \%$ agar) plates supplemented with Zeocin to select the recombinant clones. A colony blot [9] was performed to confirm the recombinant clones using anti-GnRH and anti-CT antibodies.

A recombinant clone was inoculated in BMGY medium (1\% yeast extract, $2 \%$ peptone, $1 \%$ glycerol, $400 \mu \mathrm{g} / \mathrm{L}$ biotin, and $0.1 \mathrm{M}$ potassium phosphate, $\mathrm{pH} \mathrm{6.0)}$ and incubated for grown in an orbital shaker for $24 \mathrm{~h}$ at $28{ }^{\circ} \mathrm{C}$ with an agitation speed of $250 \mathrm{rpm}$ until the $\mathrm{OD}_{600}$ of the culture reached 2-6. The cells were harvested and suspended in BMMY medium (1\% yeast extract, $2 \%$ peptone, $400 \mu \mathrm{g} / \mathrm{L}$ biotin, $1 \%$ methanol, and $0.1 \mathrm{M}$ potassium phosphate, $\mathrm{pH}$ 6.0) until they reached an $\mathrm{OD}_{600}$ of 1 . Induced expression was performed in an orbital shaker at $28 \stackrel{\circ}{ } \mathrm{C}$ with agitation speed of $250 \mathrm{rpm}$ for 5 days. Methanol was added to a final concentration of $1 \%$ every $24 \mathrm{~h}$ to maintain induction.

The recombinant $P$. pastoris expressing $\mathrm{GnRH} / \mathrm{LTB}$ were harvested by centrifugation at $5,000 \times \mathrm{g}$ for 15 min at $4 \stackrel{\circ}{\circ}$ and the supernatant was collected. Ammonium sulfate was added to the supernatant at $4 \stackrel{\circ}{ } \mathrm{C}$, adjusting the ammonium sulfate saturation to $80 \%$, and the mixture was centrifuged at $10,000 \times \mathrm{g}$ for 
$15 \mathrm{~min}$ at $4{ }^{\circ} \mathrm{C}$. The precipitated protein expressed in $P$. pastoris (pGnRH/LTB) was suspended in Phosphate Buffer Solution (PBS) pH 7.4 and dialyzed in PBS with decreasing ammonium sulfate concentration for $96 \mathrm{~h}$ and stored at $-20 \stackrel{\circ}{\mathrm{C}}$ until further analysis.

\section{GnRH/LTB E. coli expression (eGnRH/LTB)}

Plasmid $\mathrm{pPICZaB/GnRH/LTB}$ was extracted from E. coli TOP10, and the $\mathrm{GnRH} / \mathrm{LTB}$ sequence was PCR-amplified using the following primers: forward 5'-GCG AAT TCA CAA AAT GGC TCC CCA-3' and reverse 5'-CCC AAG CTT TTA CCG GGA TCC TGG ACGC-3'. PCR conditions consisted of 30 cycles of $94 \stackrel{\circ}{\circ} \mathrm{C}$ for $1 \mathrm{~min}, 55^{\circ} \mathrm{C}$ for $1 \mathrm{~min}$ and $72{ }^{\circ} \mathrm{C}$ for $1 \mathrm{~min}$. PCR product and the pAE vector were doubledigested with EcoRI and HindllI and ligated with T4 DNA ligase. The ligation product was used to transform

E. coli TOP10 cells by electroporation, and recombinant $E$. coli TOP10 cells were selected on Low Salt Luria Bertani (LB) agar plates (1\% tryptone, $0.5 \%$ yeast extract, $0.5 \mathrm{NaCl}$, and $2 \%$ agar) with $100 \mu \mathrm{g}$ ampicillin/ml. The recombinant vector $\mathrm{pAE}-\mathrm{GnRH} / \mathrm{LTB}$ was used to transform by electroporation $E$. coli BL21 (DE3) expression strain cells (Invitrogen). Recombinant clones were selected on LB plates with 100 $\mu \mathrm{g}$ ampicillin/ml and the presence of the insert $\mathrm{GnRH} / \mathrm{LTB}$ confirmed by colony blot [9] using anti-GnRH and anti-CT MAbs.

A selected recombinant clone was grown under shaking at $37{ }^{\circ} \mathrm{C}$, until $0,6-0,8 \mathrm{OD}_{600}$. The recombinant protein expression (eGnRH/LTB) was induced with $1 \mathrm{mM} \mathrm{IPTG}$ for $4 \mathrm{~h}$ at $37^{\circ} \mathrm{C}$. Bacteria were recovered by centrifugation, sonicated, and eluted in $8 \mathrm{M}$ urea. Solubilized recombinant proteins were purified by affinity chromatography using both HisTrap ${ }^{\mathrm{TM}} \mathrm{HP} 1 \mathrm{ml}$ columns pre-packed with pre-charged $\mathrm{Ni}$ Sepharose $^{\mathrm{TM}}$ and the AKTAprime ${ }^{\mathrm{TM}}$ Automated Liquid Chromatography System (GE Healthcare). Purified $\mathrm{e} G \mathrm{RH} / \mathrm{LTB}$ protein was dialyzed in PBS with decreasing urea concentrations for $72 \mathrm{~h}$ and was then stored at $-20{ }^{\circ} \mathrm{C}$ for further analysis. The concentration of the purified protein was determined using the commercial BCA Protein Assay kit (GE Healthcare). Purified protein aliquots were stored at $-70^{\circ} \mathrm{C}$ until use. I-TASSER software was used to generate the 3D predicted model from amino acid sequences [10].

\section{SDS-PAGE and Western blotting}

The proteins were boiled in SDS-PAGE loading buffer and separated on a $12 \%$ separating gel in a Mini-PROTEAN electrophoresis system (Bio-Rad). The gel was stained with Coomassie Brilliant Blue R250. For Western blotting, proteins were transferred onto a nitrocellulose membrane using a Bio-Rad Mini Trans-Blot Cell. The membrane was blocked with $5 \%$ non-fat dry milk. Antigenic proteins were detected by incubating the membrane first with anti-GnRH sera from immunized rabbits $(1: 400)$ or anti-CT MAb (1:5000) (Sigma-Aldrich), and second with anti-mouse (1:4000) or anti-rabbit (1:4000) HRP conjugated immunoglobulins. The test using anti-CT antibodies was performed because the LTB molecule exhibited more than $80 \%$ sequence identity with the subunit from Vibrio cholerae (CTB) [11]. Therefore, anti-CT antibodies were used to recognize the LTB molecule. The reactions were revealed with a solution containing DAB $(0.6 \mathrm{mg}$ diaminobenzidine, $0.03 \%$ nickel sulfate, $50 \mathrm{mM}$ Tris- $\mathrm{HCl} \mathrm{pH} 8.0$ and $15 \mu \mathrm{l}$ hydrogen peroxide).

\section{Compliance with Ethical Standards}

All mice were maintained and handled at the animal care facility from the Universidade Federal de Pelotas (UFPel), Brazil, and were housed in autoclaved cages (Alesco, Brazil) with no food or water restrictions. All procedures were performed in accordance with the Brazilian Committee for animal care and use (COBEA) guidelines and were approved by the UFPel Ethics Committee for animal research (project number 1039). All efforts were made to minimize animal suffering.

\section{Mice Immunizations}

Seven groups of ten male Balb/c mice, five-to-seven weeks old, were intramuscularly inoculated two times at an interval of 14 days as follow: group 1, $25 \mu \mathrm{g}$ of $P$. pastoris expressed GnRH/LTB (pGnRH/LTBA) adjuvanted with Montanide ISA 50 V2 (Seppic Adjuvants) (1:1, v/v); group 2, $25 \mu \mathrm{g}$ of pGnRH/LTB in PBS (pGnRH/LTB); group 3, $25 \mu \mathrm{g}$ of E. coli expressed GnRH/LTB (eGnRH/LTB-A) adjuvanted with Montanide ISA 50 V2 (Seppic Adjuvants) (1:1, v/v); group 4, $25 \mu \mathrm{g}$ of eGnRH/LTB in PBS (eGnRH/LTB); group 5, commercial anti-GnRH vaccine (Bopriva®, Zoetis) using 1/20th of a recommended dose (1 ml cattle dose with $400 \mu \mathrm{g}$, mice dose $\sim 80 \mu \mathrm{g}$ ); group 6, $25 \mu \mathrm{g}$ of E. coli expressed LTB (eLTB-A) molecule adjuvanted with Montanide ISA 50 V2 (Seppic Adjuvants) (1:1, v/v); group 7, PBS and adjuvant Montanide ISA 50 V2 (Seppic Adjuvants) (1:1, v/v). Blood samples were collected through submandibular puncture 
every 7 days until day 42 and a final blood collection was performed on day $126^{\text {th }}$. Sera were separated by centrifugation at $3,000 \times \mathrm{g}$ for $7 \mathrm{~min}$, then pooled and stored at $-20 \stackrel{\circ}{\mathrm{C}}$ for further analysis.

\section{Measurement of antibody levels}

Indirect ELISAs were performed with individual serum samples. Plates were coated overnight at $4{ }^{\circ} \mathrm{C}$ with $0.2 \mu \mathrm{g}$ of purified $\mathrm{pGnRH/LTB}$; eGnRH/LTB or eLTB per well. Serum samples were diluted 1:200, and HRP-conjugated goat anti-mouse IgG antibody (Sigma-Aldrich) was used for detection. Reactions were visualized with OPD (Sigma-Aldrich), stopped with $2 \mathrm{~N} \mathrm{H}_{2} \mathrm{SO}_{4}$, and analyzed at OD $492 \mathrm{~nm}$ using an ELISA MR 700 Microplate Reader spectrophotometer (Dynatech Laboratories).

\section{Histological analysis}

On day 42 of the experiment, 5 mice from each of the following groups: pGnRH/LTB-A (group 1), eGnRH/LTB-A (group 3), LTB-A control (group 6) and PBS-A (group 7) were euthanized by inhalation of the anesthetic isoflurane and later, during necropsy, the testicles were surgically collected for tissue analysis. The testicles were fixed for $24 \mathrm{~h}$ in Bouin's solution and were dehydrated in ascending concentrations of ethanol, cleared in xylene, and embedded in paraffin Paraplast X-tra ${ }^{\circledR}$ (Sigma-Aldrich). Next, 5- to 7- $\mu \mathrm{m}$ cross-sections were placed onto superfrost slides (Sigma-Aldrich). Slides containing tissue sections were deparaffinised in xylene, rehydrated in descending concentrations of ethanol and stained with Mayer's Hematoxylin and Eosin. Morphological changes were analyzed under an Olympus BX51 microscope at X200 and X400 magnifications.

\section{RESULTS}

\section{GnRH cloning and expression}

The expected $390 \mathrm{bp}$ of the synthetic GnRH/LTB sequence was PCR-amplified using primers for both $P$. pastoris and $E$. coli construction. Sequencing results showed that the insert was in frame with the alphafactor signal peptide and that the synthetic gene aligned perfectly with the GnRH and LTB sequences deposited in GenBank. The amplified GnRH sequence was successfully cloned into pPICZaB and pAE vectors (Figure 1a and 1b). The $\mathrm{GnRH} / \mathrm{LTB}$ protein structural model prediction, using I-TASSER software, has demonstrated that the recombinant predicted structure presents a similar conformation between $\mathrm{pGnRH}$ and eGnRH. The predicted model for the $\mathrm{GnRH} / \mathrm{LTB}$ structure can be seen in Figure 1C.

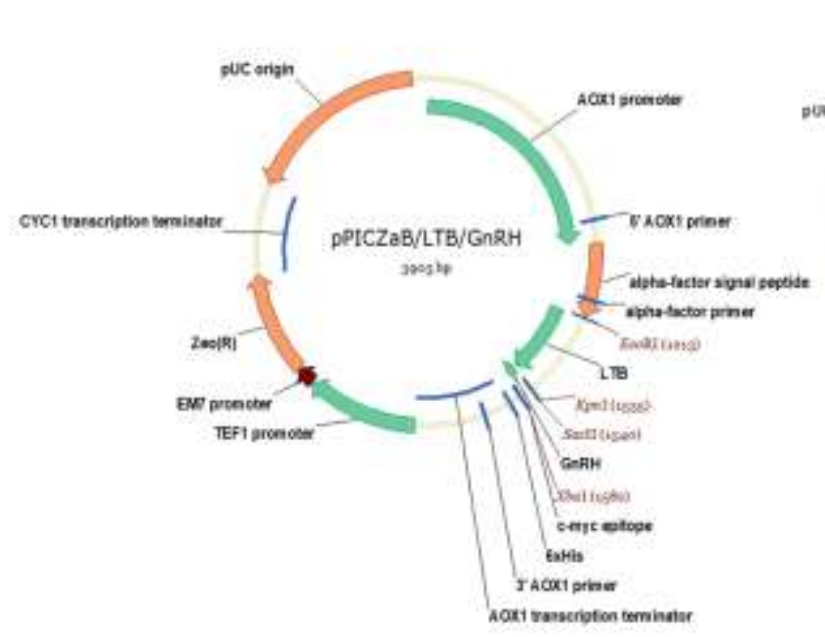

(a)

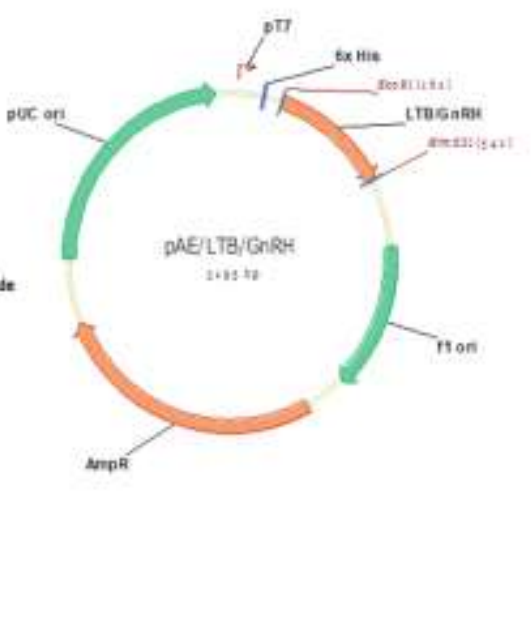

(b)

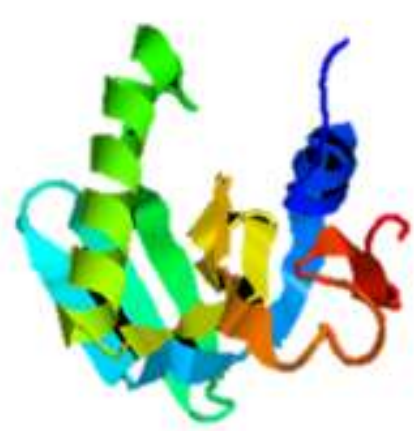

(c)

Figure 1. Silico analysis. (a) Schematic representation of the pPICZaB/GnRH/LTB vector expression (from Vector NTI Advance 10); (b) Schematic representation of the $\mathrm{pAE} / \mathrm{GnRH} / \mathrm{LTB}$ vector expression (from Vector NTI Advance 10); (c) 3D predicted model from GnRH/LTB amino acid sequences using I-TASSER software.

To evaluate protein expression and purification, SDS-PAGE was performed and showed a band of approximately $21 \mathrm{kDa}$ (Figure 2a), which suggest the expression of both pGnRH/LTB and eGnRH/LTB. Recombinants $\mathrm{pGnRH/LTB}$ and $\mathrm{eGnRH} / \mathrm{LTB}$ proteins were detected by Western blotting using rabbit 
polyclonal anti-GnRH and mouse monoclonal anti-CT antibodies (Figure $2 b$ ) in which was observe bands with approximately $21 \mathrm{kDa}$, corresponding to $\mathrm{GnRH} / \mathrm{LTB}$. The expression of $\mathrm{GnRH} / \mathrm{LTB}$ in $P$. pastoris (pGnRH/LTB) resulted in a significant increase in yield compared to expression in E. coli (eGnRH/LTB). In $1 \mathrm{~L}$ scale expression resulted in a yield of $276 \mathrm{mg} / \mathrm{L}$ of $\mathrm{pGnRH} / \mathrm{LTB}$ while $\mathrm{e} \mathrm{GnRH} / \mathrm{LTB}$ presented yield of 40 $\mathrm{mg} / \mathrm{L}$.

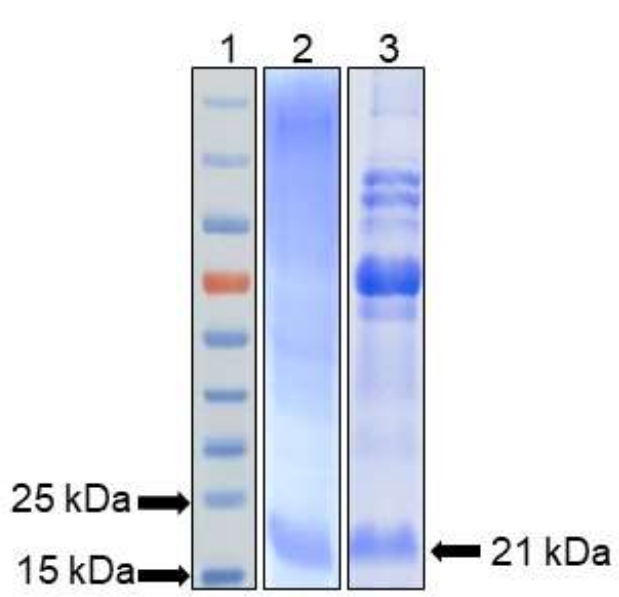

(a)

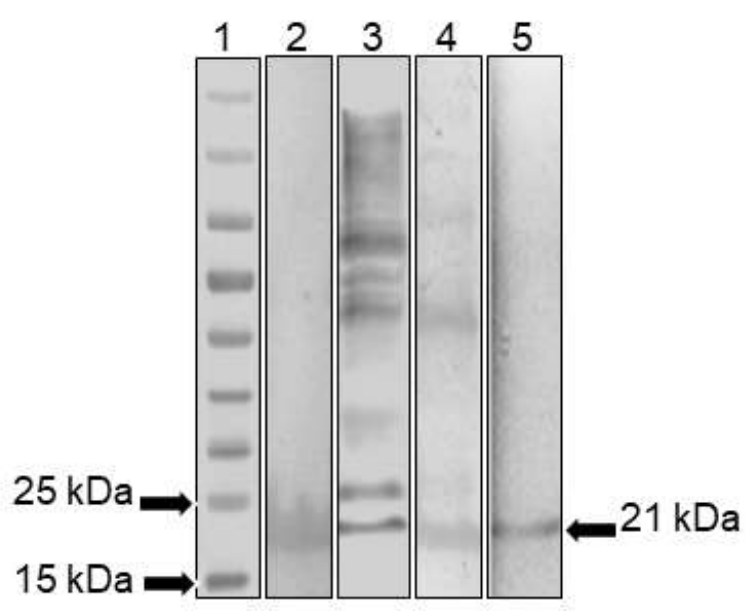

(b)

Figure 2. GnRH/LTB protein expression and characterization. (a) Profile of the recombinant $\mathrm{GnRH} / \mathrm{LTB}$ protein by SDS PAGE $12 \%$. 1. molecular weight protein ladder. 2. Purified GnRH/LTB protein expressed in P. pastoris system ( $\mathrm{pGnRH/LTB}$ ); 3. Purified GnRH/LTB expressed in E. coli (eGnRH/LTB); (b) Antigenic characterization of the recombinant $\mathrm{GnRH} / \mathrm{LTB}$ by Western blot probed with monoclonal anti-CT antibody (column 2 and 3 ) and rabbit polyclonal anti-GnRH antibody (column 4 and 5). Column 1. molecular weight protein ladder; column 2 and 4. $\mathrm{pGnRH/LTB}$ protein; column 3 and 5 eGnRH/LTB protein.

\section{Immunogenicity}

The immunogenicity of the $\mathrm{pGnRH/LTB}$ and $\mathrm{eGnRH/LTB}$ was evaluated in mice and the antibody level against the same antigens was determined by ELISA. Analyzing $\mathrm{pGnRH/LTB}$ as ELISA antigen the group that shows significant $(p<0.05)$ higher OD was the group immunized with the $\mathrm{pGnRH/LTB}+$ Montanide, followed by the $\mathrm{pGnRH/LTB}$ without adjuvant (Figure 3A). At 14th day of experiment the group 1 $(p G n R H / L T B+$ Montanide) already has a significative $(p<0.05) \sim 10$ and $\sim 7$-fold lgG increase comparing with the group 7 (control, PBS + adjuvant Montanide) and group 3 (eGnRH/LTB + Montanide), respectively (Figure $3 \mathrm{a}$ and $3 \mathrm{~b}$ ). By the $28^{\text {th }}$ day, seven days after the boost, the group 1 showed a significative $(\mathrm{p}<$ $0.05) ~ 13-$ and $\sim 11$ fold-increase comparing with control group 7 and group 5 (commercial anti-GnRH vaccine), respectively (Figure $3 a$ and $3 b)$. At $42^{\text {nd }}$ day of experiment, the group 1 has a significant $(p<0.05)$ higher OD with $\sim 14$ and $\sim 4$-fold IgG increase comparing with control group 7 and group 5, respectively. By the end of experimental days (126 days) the group 1 ( $\mathrm{pGnRH/LTB}+$ Montanide) still have the higher OD value, than commercial vaccine (group 5) and control (group7) groups (Figure 3a and 3b). 


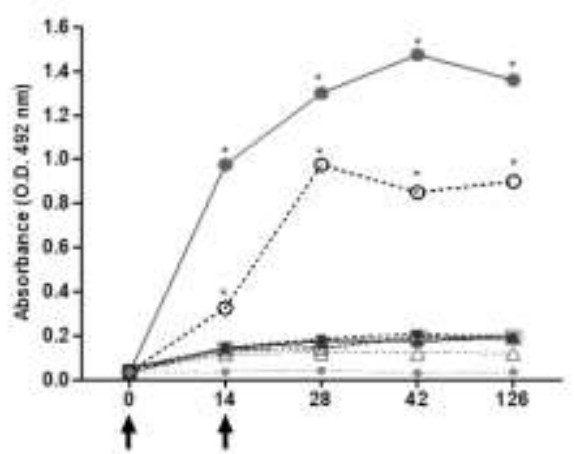

(a)

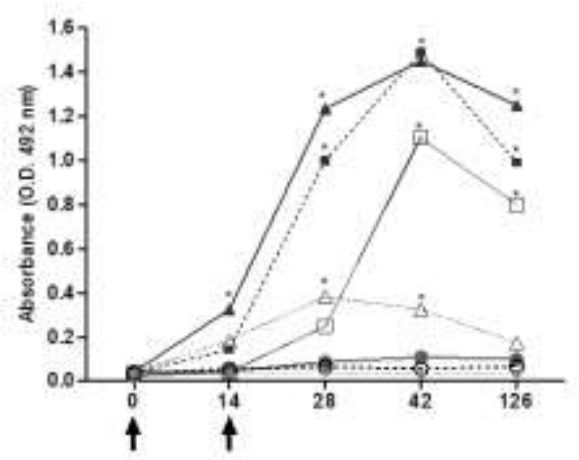

(b)

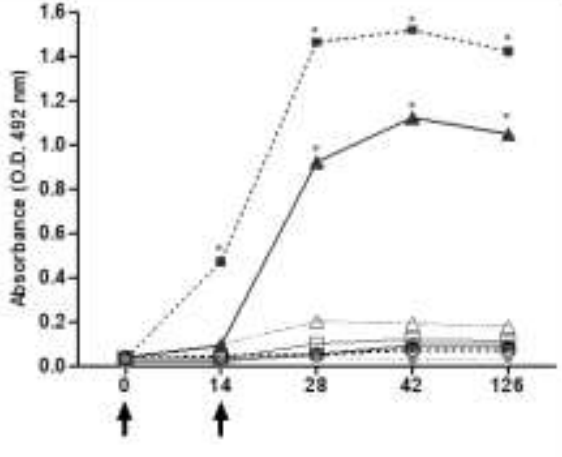

(c)

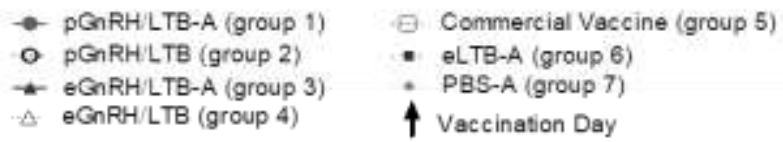

Figure 3. Humoral immune response. Total serum IgG kinetics of groups of Balb/c mice vaccinated in response to $\mathrm{pGnRH/LTB}$ (a), eGnRH/LTB (b) and eLTB (c) antigens by indirect ELISA. The animals were vaccinated on days 0 and 14 of the study. The presented results refer to the average of the absorbances obtained at $492 \mathrm{~nm}$ for sera in dilution of 1:200 (Days 0,14, 28, 42, 126) group. Significance was determined by one-way ANOVA (Tukey multiple comparison) analysis, the presence of asterisk $\left(^{*}\right)$ indicates a significant difference $(p<0.05)$ compared to the control group.

When, performing ELISA using the $\mathrm{eGnRH/LTB}$ as antigen, we observed a similar profile in antibodies response as the group 1 ( $\mathrm{gGnRH} / \mathrm{LTB}+$ Montanide), differing only by $14^{\text {th }}$ day of experiment (Figure $\left.3 b\right)$. At $14^{\text {th }}$ days of the experiment only the group $3(\mathrm{eGnRH} / \mathrm{LTB}+$ Montanide) has an OD significantly $(\mathrm{p}<0.05)$ higher than the control group. By the $28^{\text {th }}$, seven days after the boost, only the group 3 and the group 6 (LTB + Montanide) has a significantly $(p<0.05) \sim 13$ and $\sim 10$-fold increase, respectively, in lgG levels. Analyzing the $42^{\text {nd }}$ day we observed that the commercial vaccine has a significantly $(p<0.05) 10$-fold lgG increase, whereas the groups 3 and 6 showed 14-fold IgG increase, comparing with control group (Figure $3 B)$. Worth note, when used the eLTB as antigen the only two groups that respond was group 3 (eGnRH/LTB + Montanide) and group 6 (LTB + Montanide) (Figure 3c).

\section{Testicle histological evaluations}

The control group tissues immunized with LTB + Montanide (Figure 4a) and PBS group (Figure 4b) showed normal seminiferous tubules with spermatogenic cells in all developmental stages, which included spermatogonia, primary spermatocytes, spermatids and spermatozoa. In contrast with these results, tissues from the $\mathrm{pGnRH/LTB}+$ Montanide group had large proportions of seminiferous tubules without defined lumens, with the presence of detached cells in the tubules' lumens, and with few or no spermatozoa (Figure 4c). Furthermore, reductions in the concentrations of germ cells at all levels of development were observed when compared with the concentrations in the control group, suggesting a non-stage-specific inhibition of spermatogenesis following $\mathrm{GnRH}$ neutralization. Other characteristics were also observed such as the presence of vesicles permeating the germinal epithelium and sperm tail degeneration.

The $e G n R H / L T B$ + Montanide group showed similar tissue alterations as the $p G n R H / L T B$ groups. However, the alterations were more visible and well-distributed along the tissue (Figure 4d). This group had atrophy of all seminiferous tubules, absence of spermatogenesis and large reduction in the amount of Leydig cells. In all groups, these results were observed at the first analysis (2 weeks after the vaccine boost) and were sustained until the end of the experiment (16 weeks after the vaccine boost). 


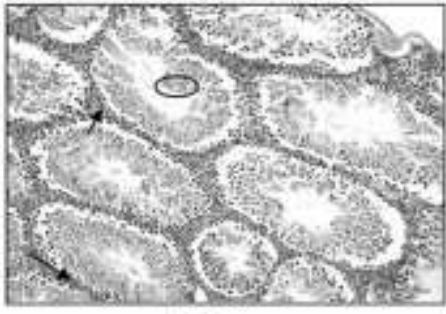

(a)

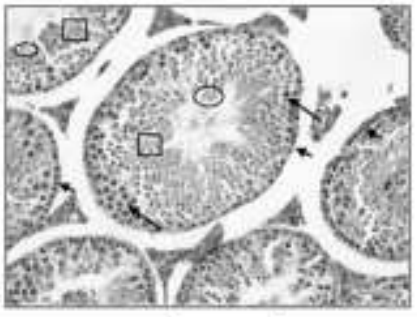

(b)

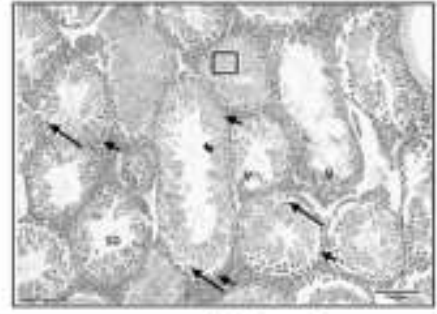

(c)

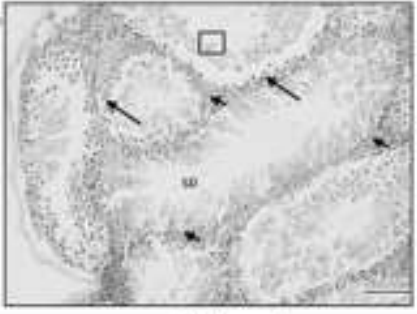

(d)

Figure 4. Gonadal histology from the LTB-A control group (a), PBS-A group (b), pGnRH/LTB-A group (c), the eGnRH/LTB-A group (d). Testes sections from day 42 were represented. Cells in spermatogenesis are shown as spermatogonia (arrows head), primary spermatocyte (arrows), spermatid (ellipse), and spermatozoa (square). $\mathrm{V}=$ vesicles. $\mathrm{SD}=$ spermatozoa degeneration. Scale bar $=100 \mu \mathrm{m}(\mathrm{a}, \mathrm{c}, \mathrm{d})$ and $50 \mu \mathrm{m}(\mathrm{b})$. Testicular tissues were stained by Hematoxylin and Eosin.

\section{DISCUSSION}

Active immunization against $\mathrm{GnRH}$ results in the production of antibodies capable of neutralizing the hormone, leading to synthesis inhibition and release of $\mathrm{LH}$ and $\mathrm{FSH}$, resulting in the blocking of steroidogenesis and gametogenesis [2,12]. Over the past decades, several alternatives have been evaluated in order to develop sterilizing anti-GnRH vaccines [13]. However, the development of a vaccine using $\mathrm{GnRH}$ as an antigen faces several challenges, being the major its poor immunogenicity. Since it is a decapeptide with low molecular weight, it is necessary to use strategies capable of stimulating the immune system to generate a response against the hormone [14]. These strategies include the construction of molecules containing multiple copies of the peptide and / or fusion with carrier proteins such as bovine serum albumin (BSA), tetanus toxoid (TT), ovalbumin (OVA) [15]. However, many carrier proteins are not well defined (e.g. variation in molecular weight, structure instability), and conjugation between the carrier and peptide may results in precipitates, but principally non-reproducible conjugation [16]. In the present study, a molecule composed by single GnRH peptide associated with a single LTB protein were constructed and expressed.

The construction was expressed in $P$. pastoris and E. coli platform satisfactory. The choice of the system and strains used to express recombinant proteins plays a major role in protein expression, principally considering solubility and yield. In general, E. coli platform is the first-choice host for the initial screening of recombinant protein expression, because these cells can be readily manipulated, are cultured inexpensively and grow rapidly (6). $P$. pastoris is another important platform for the production of recombinant proteins, especially due the ability to do post-translational modification [7]. In the present study, we were able to demonstrate that association of $\mathrm{GnRH}$ with LTB are immunogenic, and the protein expressed in both, $P$. pastoris and $E$. coli platforms, were able to induce anti-GnRH antibodies that block the hormone effect promoting histological changes on the gonads.

Evaluating the specific anti-GnRH IgG dynamic, we observed that both molecules, $p G n R H / L T B$ (GnRH/LTB expressed in P. pastoris) and eGnRH/LTB (GnRH/LTB expressed in E. coli), showed similar patter after the immunization boost. Both had a significant increase of 13 and 14 folds in $\lg$ titers at $28^{\text {th }}$ and $42^{\text {nd }}$ days, respectively, comparing with the control group (Figure $3 \mathrm{~A}$ ). Using $\mathrm{pGnRH/LTB}$ as an ELISA antigen we observed significant $(p<0.05) \mathrm{lgG}$ level only in the groups immunized with the $p G n R H / L T B$. Remarkable, was the role of the LTB as an immunogenic carrier molecule in the group 4 ( $\mathrm{pGnRH/LTB}+$ PBS, without adjuvant), exerting its adjuvant proprieties (Figure $3 \mathrm{~A}$ ). This finding is quite interesting, since it is necessary the LTB binding to ganglioside receptors (GM1) on Antigen Presenting Cells (APC), to promote antigen uptake and presentation [17]. So, one may suggest that the LTB fold in $p G n R H / L T B$ molecule was similar to the native form, allowing the recombinant protein bind to the GM1 receptor. LTB molecule forms a pentameric cylinder-like structure, responsible for binding to a cell surface receptor, the GM1 ganglioside [5], explaining the protein profile visualized in SDS-PAGE, characterized by oligomers presence.

Evaluating the ELISA using the GnRH expressed in E. coli (eGnRH/LTB), was evidenced similar tendency observed for $\mathrm{pGnRH/LTB}$. However, only the groups immunized with the molecule expressed in $E$. coli and the commercial vaccine responded (Figure $3 \mathrm{~b}$ ). Noteworthy that using eGnRH/LTB as ELISA antigen the LTB adjuvant effect was not observed, since eGnRH/LTB without adjuvant (Montanide) did not 
showed significant IgG level (Figure 3b). One may speculate that a possible reason was the codon usage, since the construction was optimized for $P$. pastoris, but expressed in $E$. coli. Interestingly, the commercial group reacts with the $\mathrm{eGnRH/LTB}$ antigen in the ELISA plates, an effect not observed when the plates were coated with $\mathrm{pGnRH/LTB}$, neither when the plates were coated with eLTB (Figure $3 b$ and $c$ ). The effect of constructions ( $\mathrm{gGnRH} / \mathrm{LTB}$ and $\mathrm{eGnRH} / \mathrm{LTB}$ ), even though not recognizing each other in the ELISA, both constructions were able to induce antibodies that block the hormone, demonstrated by significant effect on the gonads (Figure 4). One may suggest that, although the same $\mathrm{GnRH}$ amino acid sequence was used in both constructs generating similar structures, different epitopes of $\mathrm{GnRH}$ expressed in $P$. pastoris and $E$. coli were recognized by the immune system of mice. Different studies reported that the position of the carrier towards the $\mathrm{GnRH}$ molecule influencing antibodies levels, as well as specificity [16-18]. In our construction the LTB was placed at $\mathrm{N}$ terminus, and the recombinant $\mathrm{GnRH}$ molecule produced in both platforms were immunogenic, with the same IgG dynamic capable to neutralize the $\mathrm{GnRH}$ in mice. So, suggesting that was not the reason for one do not cross react with other (Figure 3). Other explanation is that different areas on the $\mathrm{GnRH}$ molecule are responsible for different physiological actions [19]. Has been reported the importance of different epitopes in the $\mathrm{GnRH}$ sequence [14] and that amino acids near to the C-terminal are important in the reproductive function of $\mathrm{GnRH}[20,21]$. Thus, one may speculate that the expression of the LTB in the two different platforms may mask different and critical epitopes. However, was out of the scope of the present study evaluate this non-cross reactivity.

Montanide ISA 50 V2 adjuvant is an emulsion composed of a mineral oil and a surfactant from the mannide monooleate family. Its adjuvant effect is mediated by the depot formation and slow release of antigen at the inoculation site, which stimulates the recruitment of APCs [22]. In the present study, we observed an increase in the specific anti-GnRH lgG suggesting its adjuvant effect in both $\mathrm{GnRH/LTB}$ constructions. These results suggested that the association with adjuvants that permit slow antigen release and prolonged induction of antibodies that block the hormone effect is extremely important for a successful immunocastration.

All mice, immunized with both molecules, $\mathrm{pGnRH} / \mathrm{LTB}$ and $\mathrm{eGnRH} / \mathrm{LTB}$, had marked gonadal alterations comparing with the control groups (Figure 4). At day $126^{\text {th }}$ of the experiment, all immunized mice showed uniform gonadal atrophy, disruption of the interstitial tissue and Leydig cell absence. Similar results were reported with a modified $\mathrm{GnRH}$ peptide fused to tetanus toxin emulsified in several adjuvants [1].

In this study we reported a novel approach of construct a recombinant protein with a single $\mathrm{GnRH}$ molecule associated with single LTB molecule, avoiding the necessity of have the $\mathrm{GnRH}$ molecule in tandem as well as the conjugation drawbacks. Both constructions presented immunogenicity in mice and were able to induce antibodies that block the hormone effect and promote histological changes on the gonads. Therefore, this is truly innovative approach, been a promising alternative for an immunocontraceptive vaccine

Funding: This work was supported by Coordination for the Improvement of Higher Education Personnel (CAPES) Brazil - Finance Code 001 and National Council of Technological and Scientific Development (CNPq).

Acknowledgments: The authors gratefully acknowledge the support to the Coordination for the Improvement of Higher Education Personnel (CAPES) - Brazil - Finance Code 001 and National Council of Technological and Scientific Development (CNPq) for LBE, PMMA a master degree scholarship, NLC and RCC a post-doctoral scholarship, ASVJ and FPLL productivity fellowship.

Conflicts of Interest: The authors declare no commercial or financial conflict of interest.

\section{REFERENCES}

1. Ferro VA, Khan MAH, McAdam D, Colston A, Aughey $E$, Mullen $A B$, et al. Efficacy of an anti-fertility vaccine based on mammalian gonadotrophin releasing hormone $(\mathrm{GnRH}-\mathrm{I})$ - A histological comparison in male animals. Vet Immunol Immunopathol. 2004;101(1-2):73-86.

2. Gupta SK, Bansal P. Vaccines for immunological control of fertility. Reprod Med Biol. 2010;9(2):61-71.

3. Han X, Ren X, Zeng Y, Zhou Y, Song T, Cao X, et al. Physiological interactions between the hypothalamicpituitary-gonadal axis and spleen in rams actively immunized against $\mathrm{GnRH}$. Int Immunopharmacol. 2016;38:27583.

4. Rock EP, Reich KA, Lyu DM, Hovi M, Hardy J, Schoolnik GK, et al. Immunogenicity of a fusion protein linking the beta subunit carboxyl terminal peptide (CTP) of human chorionic gonadotropin to the $B$ subunit of Esherichia coli heat-labile enterotoxin (LTB). Vaccine. 1996;14(16):1560-8. 
5. Nashar TO, Betteridge ZE, Mitchell RN. Evidence for a role of ganglioside GM1 in antigen presentation: binding enhances presentation of Escherichia coli enterotoxin B subunit (EtxB) to CD4(+) T cells. Int Immunol. 2001;13(4):541-51.

6. Peleg Y, Prabahar V, Bednarczyk D, Unger T. Heterologous Gene Expression in E.coli. Methods Mol Biol [Internet]. 2017;1586:33-43.

7. Baghban R, Farajnia S, Ghasemi Y, Mortazavi M, Zarghami N, Samadi N. New Developments in Pichia pastoris Expression System, Review and Update. Curr Pharm Biotechnol. 2018;19(6):451-67.

8. Chen X, Zaro JL, Shen WC. Fusion protein linkers: Property, design and functionality. Adv Drug Deliv Rev. 2013;65(10):1357-69.

9. Goodnough MC, Hammer B, Sugiyama H, Johnson EA. Colony immunoblot assay of botulinal toxin. Appl Environ Microbiol. 1993;59(7):2339-42.

10. Roy A, Kucukural A, Zhang Y. I-TASSER: A unified platform for automated protein structure and function prediction. Nat Protoc. 2010;5(4):725-38.

11. Spangler BD. Structure and function of cholera toxin and the related Escherichia coli heat-labile enterotoxin. Microbiol Rev. 1992;56(4):622-47.

12. Lee YJ, Jo EJ, Lee HW, Hwang BR, Kim YH, Park BJ, et al. Evaluation of infertility efficy of the E. coli expressed STF2-GnRH vaccine in male cats. J Vet Sci. 2019;20(3):1-9.

13. Naz RK, Saver AE. Immunocontraception for Animals: Current Status and Future Perspective. Am J Reprod Immunol. 2016;75(4):426-39.

14. Silversides DW, Allen AF, Misra V, Qualtiere L, Mapletoft RJ, Murphy BD. A synthetic luteinizing hormone releasing hormone vaccine. I. Conjugation and specificity trials in BALB/c mice. J Reprod Immunol. 1988 Aug 1;13(3):249-61.

15. Sharma S, McDonald I, Miller L, Hinds LA. Parenteral administration of GnRH constructs and adjuvants: Immune responses and effects on reproductive tissues of male mice. Vaccine. 2014;32(43):5555-63.

16. Beekman NJCM, Schaaper WMM, Turkstra JA, Meloen RH. Highly immunogenic and fully synthetic peptidecarrier constructs targetting GnRH. Vaccine. 1999;17(15-16):2043-50.

17. Haan LDE, Verweij WR, Feil IK, Holtrop M, Hol WGJ, Agsteribbe E, et al. Role of. Immunology. 1998;94:424-30.

18. Goubau S, Silversides DW, Gonzalez A, Laarveld B, Mapletoft RJ, Murphy BD. Immunization of sheep against modified peptides of gonadotropin releasing hormone conjugated to carriers. Domest Anim Endocrinol. 1989;6(4).

19. Nikiforovich, Gregory V. Marshall GR. Conformation-function relationships in LHRH analogs: I. Conformations of LHRH peptide backbone. Int J Pept Protein Res. 1993;42(2):171-80.

20. Gupta HM, Talwar GP, Salunke DM. A novel computer modeling approach to the structures of small bioactive peptides: The structure of gonadotropin releasing hormone. Proteins Struct Funct Bioinforma. 1993;16(1):48-56.

21. Flanagan CA, Becker II, Davidson JS, Wakefield IK, Zhou W, Sealfon SC, et al. Glutamate 301 of the mouse gonadotropin-releasing hormone receptor confers specificity for arginine 8 of mammalian gonadotropin-releasing hormone. J Biol Chem. 1994;269(36):22636-41.

22. Şahar EA, Can H, Iz SG, Döşkaya AD, Kalantari-Dehaghi M, Deveci R, et al. Development of a hexavalent recombinant protein vaccine adjuvanted with Montanide ISA $50 \mathrm{~V}$ and determination of its protective efficacy against acute toxoplasmosis. BMC Infect Dis. 2020;20(1):493. 